\title{
REINTERPRETING INDUSTRIAL ECOLOGY
}

\author{
Paul D. Jensen, Lauren Basson \& Matthew Leach
}

\section{Summary}

This article argues that industrial ecology has, to date, largely engaged with the ecological sciences at a superficial level, which has both attracted criticism of the field and limited its practical application for sustainable industrial development. On the basis of an analysis of the principle of succession, the role of waste, and the concept of diversity, the article highlights some of the key misconceptions that have resulted from the superficial engagement with the science of ecology. It is argued that industrial ecology should not be seen as a metaphor for industrial development; industrial ecology is the ecology of industry and should be studied as such. There are manifold general principles of ecology that underpin our understanding of the world; however, the physical manifestation and causal effects of these principles are particular to the system and its constituent elements under analysis. It is thus proposed that context-specific observation and analysis of industry are required before theoretical and practical advancement of the field can be achieved.

\section{Introduction}

The premise that the science of ecology and, more specifically, the metaphoric mimicry of natural ecosystems can lead to greater conservation of resources and wider environmental protection continues to be fundamental to industrial ecology researchers and practitioners alike. The study and, to a lesser extent, practice of industrial ecology have been a conceptual source of hope for sustainable industrial development for at least two decades. The publication of the article by Frosch and Gallopoulos (1989) entitled "Strategies for Manufacturing" arguably signaled the start of a concerted effort to model industrial processes on those widely observed within the biosphere. The assumption is that by modeling industrial systems on seemingly resource-efficient and harmonious biological ecosystems, it is possible to reorganize the environmentally damaging and resource-wasteful industrial systems that humans increasingly rely on, to function in a more environmentally benign and resourceful manner. Despite the passing of more than two decades since "Strategies for Manufacturing" was first published, however, there has been slow progress made on both the theoretical 
development of industrial ecology and, in particular, the practical application of its guiding principles for cleaner production and resource efficiency. The lack of progress within the field of industrial ecology, particularly in relation to implementation, has been attributed to several factors. Some commentators would assert that the lack of progress is due to the source metaphor being inappropriate, primarily because of fundamental differences that (seemingly) exist between human industry and ecosystem functioning (e.g., Ayres 2004; see also the discussions presented by Korhonen 2005 and McManus and Gibbs 2008). Others, meanwhile, surmise that the active development of so-called eco-industrial parks is unlikely to happen because it is difficult, particularly at the planning level, to attract and coordinate the number and diversity of companies (and other organizations) that are required to form the basis of any self-sufficient industrial ecosystem (e.g., Ehrenfeld and Gertler 1997; Gibbs and Deutz 2005, 2007; Chertow 2007). In effect, it is suggested that human factors, such as the need for trust and cooperation, and economic factors, such as the self-centric need to strive for business growth, obstruct the planned development of networked, interacting, industrial ecosystems. Thus, biological ecology, other than at a highly conceptual and metaphoric level, is seemingly not a suitable science for informing greater resource efficiency.

This article argues, however, that any misgivings or criticisms that are held in relation to employing ecology as a suitable guide for sustainable industrial development are based on a lack of knowledge of the source science or a lack of appreciation of what ecology fundamentally pertains to.

\section{The Need for Reinterpretation}

Philosophical Thinking and Knowledge Deficiency

To date, industrial ecology theory has largely been presented on a desirability basis and the 'cherry-picked' principles ${ }^{1}$ of ecology are regularly applied (or dismissed) in a superficial manner with surprisingly little or no reference to ecological research. Several studies have engaged with the wider principles of ecology and the literature of the source science (e.g., Nielsen 2007; Mayer 2008; Ashton 2009). But, in many cases, arbitrary principles of ecology are routinely applied in an overarching manner that is not suited to providing the levels of complex analysis required to yield sound reference points for sustainable industrial development (discussed below and in the following section). Hence, it is readily apparent why tangible eco-industrial development remains largely elusive and why 
some researchers are seemingly able to dismantle much of the theory behind industrial ecosystem thinking (e.g., Harte 2001; Levine 2003; Ayres 2004).

The science of ecology does not pertain to the prescription of normative ideals. It does not seek to provide a metaphoric basis for anything. And, due to inherent idiosyncrasies, many principles of ecology do not manifest themselves in a universally causal or easily predictable manner. Indeed, of the universally held principles and laws of ecology that do exist, many derive from the study of physics or chemistry. ${ }^{2}$ Ecology, as one of the natural sciences, intrinsically relates to observation, interpretation, and, one hopes, understanding (and, where appropriate, prediction). On the basis, first and foremost, of observation and interpretation, ecologists seek to answer specific questions or simply try to better understand the world we live in. If applied correctly, ecology is one of the most powerful sciences available to humans in relation to understanding the ways in which the world works. It is also, by far, one of the most complex of scientific fields to truly understand (Wilson 2001).

As a consequence of the complexity involved in the study of ecology, and despite how the subject is regularly portrayed in industrial ecology literature, it is still a science that contains many uncertainties and is certainly not capable of informing industrial development in an all-encompassing manner. Indeed, despite over a hundred years of studying the world from the perspective of ecology, most ecologists will readily admit that they have only scratched the surface of the complexity involved in observing living systems and the ways in which they interact and develop (Chapman and Reiss 1999). It seems that many industrial ecologists are largely unaware of, or fail to acknowledge, the levels of uncertainty that exist within the wider study of ecology.

Ecology, for the most part, is not an exact science in which each principle or theory applies to every organism or system under analysis in a uniform manner (that said, see the work of Jørgensen [2002] for a discussion on the existence of universal ecosystem processes and properties). In reality, disagreements within the ecological sciences are rife. One brief search through journals such as Ecology or Oikos or through one of the core ecology textbooks (e.g., Begon et al. 2006) would highlight the levels of debate and apparent disagreement that exist within the field (the ongoing diversity-stability debate is a prime example). Indeed, considerable debate has taken place on the very question of whether any universally applicable principles or laws ${ }^{3}$ exist in ecology (e.g., Lawton 1999; Colyvan and Ginzburg 2003; Hansson 2003; Lange 2005; O’Hara 2005). Consequently, from a practical implementation stance, there is little to be gained from selecting what are effectively arbitrary 
ecological principles (e.g., Korhonen's [2001a] widely cited four principles for an industrial ecosystem) and applying them to industrial development in an all-encompassing or metaphoric manner. It is important to fully engage with ecological theory on a contextspecific basis, otherwise the idiosyncrasies of individual principles and their many sound applications (and well-documented failings) could be missed. Any detractors of the underlying concepts of industrial ecology are, in effect, simply highlighting deficiencies in the applicability of many principles that have, for numerous years, already been recognized and widely debated by biological ecologists.

Due to widespread misuse, there have been suggestions that the very word ecology has escaped the controls of academia and been wrongly portrayed as a quasi-scientific philosophy for life, rather than a dedicated branch of the biological sciences (Westoby 1997). Surely the accusation of quasi-scientific philosophy is not a fate any researcher would wish to befall the study of industrial ecology. At a basic level, it is thus fundamentally wrong to reduce the field to the frail conceptual level of a metaphor (or paradigm) for environmentally benign industrial development. Portraying industrial ecology as a metaphor, at any scale, only leaves the field open to criticisms of ineffectual thinking and to potentially undermining statements such as: “...industrial systems will never operate as nature does" (Korhonen 2001b, 66). How, precisely, does 'nature' operate? Does 'nature' refer to the entire biosphere, a particular biome, an ecosystem, an individual habitat, or something else? What form of industry are we referring to: all industry, an individual company, or a specific industrial sector? Industry, as a product and 'servant' of a living system, the human system, is as valid a research element of the ecological sciences as those studied within any other autoecological ${ }^{4}$ study. Industrial ecology is the ecology of human industry and should be studied as such. It should not be trivialized and left open to detrimental criticisms that, as Gallopoulos (2006) suggests, can follow concepts that are seemingly underpinned on philosophical ideals.

\section{Practice Before Prescription}

The employment of philosophical metaphors (rather than ecological empiricism) to explain or dictate what occurs within the anthrosphere does nothing more than perpetuate the (repeatedly calamitous) belief that we are custodians of the natural world rather than one small element of the wider biosphere. Indeed, in providing legitimacy to metaphoric thinking, several industrial ecology articles are seemingly constructed around the belief that humans do 
indeed transcend the natural environment (e.g., Boons and Roome 2001; Ehrenfeld 2003; Wells 2006). The belief that human industry is not part of nature and anything we do or aspire to do is not entirely subject to the limiting factors of our one planet is fundamentally absurd and should be avoided if industrial systems are to be observed in an objective ecological manner.

Ecological principles and ecosystem science must be applied to industry in the same manner as they are applied to, say, a given form of woodland, a particular species of tree within the woodland, or a particular community of species that makes the tree its home. Essentially, ecologists define specific questions about the ecology of a given organism or system that they are interested in prior to observing the subject matter under suitable study conditions. Observations made are interpreted in a manner suited to answering the original question in hand. Fundamentally, the ecologist has an answer to a specific question; he or she rarely possesses an answer or principle that is suitable for direct application to all queries or observed ecological phenomena. By their very nature, all complex systems (biological or otherwise) are dynamic, and hence many principles of the ecological sciences must, where necessary, be dynamic and thus be molded to fit observed circumstances. Indeed, if one wishes to intrinsically understand the ecology of saltmarsh, one studies saltmarsh. Although they largely require the same fundamental resources to function and are subject to similar evolutionary forces, one would not study the ecology of mangrove and expect to possess knowledge suited to predicting the potential future of saltmarsh. This perhaps extreme example could be applied at any ecological level from, say, genotype to organism to community to the given example of ecosystems, but the overriding message is applicable to the study and practice of industrial ecology.

A company or, more likely, industrial sector must be ecologically analyzed in its own right to determine its past and, potentially, future course of evolution (and any new feedback mechanisms resulting from its evolution). As a community, industrial ecologists need to increase research into the ecology of industry, rather than speculating on its idealized future. Existing principles of biological ecology that can be shown to provide sound analogues between industrial systems and biotic systems should be accepted and widely promoted. Frivolous reinterpretation of the language or lessons of ecology should be avoided. Where, however, principles (or ecological analysis tools) clearly do not fit industrial development in general, or do not fit specific industrial sectors, they should be disregarded or reinterpreted to 
suit the given situation. This is what happens within all the traditional branches of ecology; this is what should happen with industrial ecology.

Ecosystem science alone provides a myriad of enlightening system genesis, development, and maintenance principles that industrial ecologists can apply on a testable basis if it is accepted that there is no contradiction in the literal analysis of industrial systems on an ecological basis. Indeed, it has been recently argued that "...real industrial ecology..." can only occur once a full understanding of the current conditions of industrial systems, in relation to our knowledge of ecosystem functioning, is acquired (see Nielsen and Müller 2009, p. 1914). The potential need to reinterpret existing principles of ecology to fit what is witnessed within industrial systems does not translate as the rejection of ecology as a suitable platform for promoting sustainable industrial development; it translates as the evolution of industrial ecosystem science.

All fledging scientific fields develop in a haphazard, opportunistic manner (Wilson 2004). After at least two decades of development, however, it is time for industrial ecology theorists to concentrate on specificity. The age of opportunism that saw the promotion of the ecological metaphor has arguably reached its natural (and very limited) conclusion. Only after appropriate principles of ecosystem development are categorically shown to be applicable to industry (and demonstrated to policy makers) can industrial ecology be taken seriously as a science capable of delivering tangible eco-industrial development.

To consolidate what has been stated here, industry is as valid an ecological study subject as any other product of a given organism's continuing adaption to its environment and its compulsion to fulfill its daily needs. As a consequence, industrial ecosystems do not require creation; they already exist, albeit in a (largely) resource-inefficient form. It will be argued that at the initial points of system genesis and succession, they do develop in accordance with the same 'principles' and 'laws' as all other ecosystems. At the community development and functioning levels, however, the sheer magnitude of complexity and innumerable system feedback mechanisms mean that many existing ecological principles are unlikely to be directly transferable in their raw form. It is thus argued that discovering when and where existing principles of ecology are applicable, when and where they require adaption, and when alternative principles require creation, constitutes the study of industrial ecology and, ultimately, the development of the principles of industrial ecosystem science. 
To continue the core argument of this article, some of the regularly proposed core principles of industrial ecology that generate criticism and debate from both detractors of industrial ecology and natural ecologists alike will be highlighted. By way of conclusion, the article endeavors to highlight the necessity to perform and consult ecology in a literal and case-specific manner and, in the process, attempts to also provide an insight into the intrinsically complex nature of the science and study of ecology.

\section{Misconception, Contradiction, and Debate}

One potential criticism of using ecosystems as a source model for industrial development is the belief that the two systems seemingly operate according to fundamentally different principles of evolution and maintenance. Due to internal recycling and system inputs primarily deriving from renewable sources, it is widely believed that ecosystems are inherently resource efficient and thus sustainable. In contrast, it is suggested that industry is inherently unsustainable due to the linear nature of resource movement and energy inputs primarily deriving from non-renewable sources (e.g., Frosch and Gallopoulos 1989; Jelinski et al. 1992; Graedel 1996; Korhonen 2001a; Korhonen et al. 2004; Gibbs 2008). Superficially, these differences between the two systems seem undeniable; however, as will be argued, the apparent differences only exist due to misconception or inappropriate spatial or temporal comparisons being made.

\section{System Genesis and Succession}

The laws of thermodynamics are the biggest constraint to production within industrial and natural ecosystems (Nielsen 2007) - this position is irrefutable. Exactly how the laws of thermodynamics manifest themselves within the evolution of biotic systems is, however, a point of debate. Without an exposition of the widely discussed relationship between thermodynamic efficiency and system development, it can be safely stated that at the point of genesis, the global industrial system developed, and continues to develop, along the same macroecological principles and laws as any other ecosystem (for chronological discussion on thermodynamics and ecosystem development, see Lotka 1922a, 1922b; Odum and Pinkerton 1955; Schneider and Kay 1994; Jørgensen 2002). 
At the point of colonization, the primary (and secondary) genesis of habitats occurs with the appearance of select pioneer species that, via their fundamental niches, ${ }^{5}$ are adapted to sequestering and assimilating underutilized in-situ resources (Chapman and Reiss 1999; Begon et al. 2006). As pioneer species take hold within a habitat, they systematically, by their very appearance, create or facilitate further fundamental niches that provide and provoke, through system feedback, multispatial habitat change and the development of new resources or the release of existing resources. As later sere ${ }^{6}$ organisms fill and exploit the newly evolved fundamental niches, the process of niche opening and realization occurs on a continual basis in continued response to internal system changes. As this process of autogenic succession, as it is termed, takes place, and an ecosystem continues to develop, community structure typically evolves toward diversification until the ecosystem reaches a point of relative temporal stability (Chapman and Reiss 1999). In many cases, the primary colonizers that set system evolution and diversification in motion, with their unlocking of previously difficult-to-utilize resources, become victims of their own success as they promote the development of ecosystems that are rich in competition or simply no longer suited to their maintenance or, more specifically, their fecundity (Chapman and Reiss 1999; Begon et al. 2006). The unintentional but self-propagated changes to a given habitat, such as the modification of soil chemistry or structure through an accumulation and decomposition of leaf litter, which are disastrous for many incumbent species, are essential for the appearance of others. Neither organic nor industrial pioneers intentionally make their 'homes' less suited to their proliferation; stochastic and potentially undesirable environmental change is an inevitable consequence of their existence and their necessary resource (in the widest sense) exploitation (for a discussion on the general trends of system succession, see Odum 1969).

In direct comparison, it can be stated that the Industrial Revolution blossomed on the back of the exploitation of vastly underutilized resources in the same way pioneer primary producers exploit seemingly bare earth. The evolved ability to exploit underutilized sources of energy and thus develop greater system production capacity generated unprecedented industrial development and, consequently, significant changes in the local and wider environment. As the technosphere has developed and diversified on the back of continued resource innovation and fundamental (techno) niche realization, increased resource competition and environmental change have been generated. Over the last two centuries, the accumulation of environmental 'bads' (from a human perspective) has promoted successional forces within the technosphere that have, in turn, promoted changes to the way we allow the 
industrial ecosystem to proliferate. For example, the systematically evolved physical and political tools of cleaner production can be seen as a clear response to the autogenic poisoning and degradation of the human habitat.

Due to our higher cognitive skills, we are effectively able to recognize impending phases of autogenic succession and thus adapt or evolve far quicker than most colonizer species. Thus, the levels of industrial adaption and diversification that are capable of facilitating greater resource efficiency do not necessarily evolve due to a perceived lack of immediate necessity. Arguably the forces of autogenic (or possibly allogenic ${ }^{7}$ ) succession can, however, only be avoided for so long before industry, in its current form, degrades the human habitat to a point where it succumbs to succession and perishes or adapts in a way best suited to reaching relative environmental stability. In the same manner as many other colonizers become victims of their own success, resource-inefficient and environmentally degrading industry will, no doubt, eventually become a victim of its own considerable success.

Whilst fundamental niches continue to exist within immature 'habitats', geographic dispersion will, however, take place - industrial practices that have succumbed within industrially evolved countries invariably continue to colonize and prevail within newly industrialized countries. The components of all systems will, if allowed by adaption or lack of competition, take the least resistance or 'easy' existence and development option until such time as environmental influences dictate that adaption (or extinction) is a necessity. The 'easy' option and the feedback controls required to promote the necessity (or will) to evolve will differ vastly between systems and the specific components that constitute a given system's community because, in the process of realizing a fundamental niche, a given company or industry must, by definition, be locally adapted. ${ }^{8}$

The idea that local factors may be important to the understanding of industrial ecology is not new. It has been widely acknowledged that the development (or nondevelopment) characteristics of individual industrial ecosystems are affected by local factors (e.g., Korhonen, 2001a; Baas and Boons 2004; Roberts 2004; Deutz and Gibbs 2008). Like all systems, industry is subject to the physical and temporal availability of the resources that allow it to function. Thus, on one level or another, there must be locally present influences and instances of operational feedback that allow a given industrial ecosystem to proliferate. Although it is difficult to ascertain what is controlling what within an ecosystem (Nielsen 2007), ascertaining what system development and proliferation influences exist within 
individual industrial ecosystems, at a specific geographic scale or on a sectoral basis, will allow a more complete, but admittedly complex, picture of potential industrial evolution to be painted. Ultimately, however, industrial ecologists need to remember that everything in the present is a product of the past; arguably, nothing in nature is adapted to the future.

\section{Nature: The Perfect Recycler?}

Biological ecosystems are driven by circular recycling of resources; in contrast, industrial systems are outwardly characterized by linear movement of resources and the accumulation of waste (e.g., Graedel 1996; Ehrenfeld and Gertler 1997; Korhonen 2001a; Korhonen et al. 2004). It is widely believed that, as: “...masters of recycling...” (Korhonen 2001b, 57), ecosystems generate: “...little or no waste” (Roberts 2004, 998). In many ways, these statements are perfectly sound, and, thus, as a core tenet of industrial ecology theory, the goal of emulating the status of 'master' recycler within industrial ecosystems is an admirable one. These statements are also technically incorrect, however, as at any one time, vast amounts of waste exist within individual ecosystems and the wider biosphere (as also acknowledged and demonstrated by Levine [2003] and Ayres [2004]).

Fossil fuels, our primary energy source and, arguably, the source of contemporary industry, are a waste product of nature's 'incomplete' biological assimilation of ancient carbon-based life. Many of the materials we employ in construction activities are formed from waste products that have not been fully assimilated by the environment. One of many possible examples is limestone, which is primarily composed of the calcite remains of longdead marine organisms. The current composition of our atmosphere is the product of waste generation: prior to the appearance of life on Earth (and, by definition, ecosystems), the balance of elements that were found in the planet's atmosphere differed vastly from its present composition. Indeed, without the oxygenic 'pollution' of the atmosphere, humans (and, arguably, all eukaryote life forms) would not exist! Numerous further apparent instances of waste in the environment could be presented to highlight the fact that waste, as we perceive it, does indeed exist within the biosphere. Furthermore, the notion of closed cyclical systems can be automatically debunked, at least at the local scale, with the knowledge that ecosystems regularly lose and gain resources through instances of wet-fall, dry-fall, gaseous atmospheric dispersion, and in-situ consumption or collection by organisms prior to ex-situ deposition (see Begon et al. 2006). 
If ecosystems are not as resourceful (and locally closed) as we are led to believe they are, the question thus arises: is internal or externally deposited waste actually a bad thing, or is it simply a human construct that has no meaning in ecology? In some cases, 'waste' is arguably good. The accumulation of waste and perceived pollution or degradation of a given ecosystem is often the precursor to evolution and the emergence of diversity and, consequently, increased resource optimization - this, in part, is the basic but much debated principle of (autogenic) succession. Waste is only seen as bad when it impinges on or threatens the long-term existence of a given organism. Waste, in effect, does not exist; it is a force of evolution within both systems and should be studied as such within industrial ecology. Indeed, the perception that industrial ecosystems are wasteful due to the linear movement of materials only exists if one puts a spatial or temporal boundary around a study site. With the knowledge that waste does exist in nature and that ecosystems are not completely cyclical, it could be easily argued (and proved) that ecosystems are also linear systems if, again, one does not extend the study boundary (both in time and space).

Effectively unused by-products emanating from processes within industrial (and biological) systems have not become system waste; they have simply entered resource sinks similar to those that exist within all ecosystem compartments. Any resource sink will perpetuate within an ecosystem until such time as an organism or process enters the system or evolves that is capable of directly using or assimilating the said waste product. Given sufficient time, there is always the possibility that something will evolve that can economically, thermodynamically, or chemically assimilate or make best use of a resource, regardless of how unlikely that may seem at a given point in time. For example, if over several millions of years humans had not evolved into their specific niche and had not continued to realize many fundamental niches, resource sinks such as crude oil would, from the perspective of many other elements of nature, remain a useless and potentially harmful waste product. This example and general line of thought reiterates a core question within industrial ecology theory: where is the boundary, if one exists, between industrial and biological systems? More specifically, when does the human system start, or stop, being part of wider biosphere evolution and functioning?

It is accepted that undesirable and potentially disastrous side effects are associated with the unlocking of some resource sinks that are deemed to be examples of waste within nature. For an obvious example, the release of carbon dioxide is a seemingly undesirable side effect of the use of fossil fuels. If anthropogenic cognition is taken out of the theoretical 
equation, however, there are no undesirable side effects emanating from our use of ecosystem by-products. We have simply created new environmental influences. Waste, or, in effect, the existence of a new resource or successional influence within the environment is a precursor and force behind evolution and invariably the appearance of further optimized systems. It is undeniable, however, that our biggest problem, as a species, is the rate at which environmental 'problems' are multiplying, persisting and thus potentially threatening our current way of life. But, without suitable consideration of (and swift reaction to) the consequences of our actions, this is seemingly an inevitable and typically unpredictable consequence of niche realization and consequent resource exploitation.

\section{Diversity and Ecosystem Functioning}

It has been argued that industrial diversity is essential to the functioning and stable development of industrial ecosystems (e.g., Côté and Smolenaars 1997; Korhonen 2001a, 2001b; Korhonen and Snäkin 2005; Ashton 2009; Liwarska-Bizukojc et al. 2009). It is widely believed that increased diversity and, consequently, collective adaptability are able to protect against harmful perturbations in the local and wider environment. It is also believed that the increased number of potential system linkages that derive from system diversity also promote the possibility of localized by-product reuse and, thus, increased productivity (Korhonen 2001a, 2001b; Hardy and Graedel 2002; Sterr and Ott 2004; Korhonen and Snäkin 2005; Liwarska-Bizukojc et al. 2009). At the highest point of application, these statements are both sensible and intuitive within the development and understanding of both industrial and biological systems theory. When parallels are drawn between observations made within biological and industrial ecology, however, there is a belief that industrial systems typically develop toward homogenization of production and, in some cases, monopolies, which is in contrast to the individuality and diversity that exists within ecosystems (Nielsen 2007; Ashton 2009). Arguably, however, this divergence between the two systems does not strictly exist. Individual species do dominate at various successional seres and would, no doubt, evolve toward a full monopoly of resources and habitat 'markets' if suitable environmental conditions existed and their fundamental niche allowed such domination. For instance, many mature ecological communities can be almost entirely dominated by a singular species of plant life. Indeed, the common reed ( $P$. australis) has been known to develop 'natural monocultures' that cover vast areas of wetland. 
Although the likes of the common reed can entirely dominate the plant life within a given area (on many scales), it is debatable to what extent it exists in biotic isolation (i.e., nutrient uptake is largely facilitated by symbiotic mycorrhizal fungi, and the stands form a refuge for many animals). Furthermore, their continued dominance at a given point in time is continually subject to stochastic and potentially destructive forces (e.g., storms and disease) that could lead to the reopening of a given area's resources to a wider group of species. In parallel to this example, it is debatable to what extent a given industry can or does operate in isolation or how long any company can continue to monopolize the use of a resource or the share of a market. As evidenced by the recent world economic downturn, even the most dominant of companies are subject to, and can ultimately be victims of, wider market forces beyond their control.

Discussion on the potential benefits of diversity and its effects on overall system stability and levels of production have to be conducted in a context-specific manner. Diversity, in the sense of the richness and relative abundance of system elements, simply provides options for adaptability. In theory, diversity is excellent for promoting system productivity and stability; however, these system traits could, arguably, be achieved by a small number of companies if they are sufficiently adaptable and prepared for change or prepared to exploit an opportunity to evolve toward a 'fitter' state of existence. Neither internal nor system diversity, however, guarantees an increase in the productive efficiency of the individual or the system as a whole. Indeed, as our current economic systems are largely driven by finite resources, the efficiency of our productions systems is arguably a far more important aspect of ecosystem functioning to focus on than, for example, a dogmatic consideration of productivity or the increased cycling of materials.

Ultimately, system efficiency and stability (in the form of resilience and, initially, resistance) cannot be boiled down to a generalized belief that more diversity equates to desirable system characteristics. Such a statement needs empirical testing at various scales within defined industrial ecosystems, not least because several researchers have conducted subject-specific research that concludes that a positive relationship between biotic diversity, per se, and overall system stability is not as universal as one would intuitively believe it to be (see McCann 2000; Cameron 2002; Pfister and Schmid 2002). Indeed, although increased productivity, in the form of primary production, has been largely shown to be a product of increased species richness (e.g., Tilman et al. 2001; Hooper et al. 2005; Flombaum and Sala 
2008), the effects (or at least our understanding) of diversity on system stability and productive efficiency are less conclusive.

The increases in productivity that are seen to be a product of species richness are, in general, intuitively believed to be a result of increases in both spatial and temporal resource complementarity (i.e., niche differentiation and facilitation), which follow the maturation and diversification of a system ${ }^{9}$ (Cardinale et al. 2007). Apart from productivity, it is probable that complementarity and functional traits, at and between multiple trophic levels, are important to the development of all ostensibly positive ecosystem properties. Acquiring a greater understanding of the development of genotypic and phenotypic traits is almost certainly the best way to derive a fuller knowledge of system diversity and, in particular, its context-specific causal properties and 'benefits'. Unfortunately, research into which and how many species act in a complementary way has not been widely conducted (Hooper et al. 2005). Moreover, in specific relation to the long-running diversity-stability debate, it has been suggested that research has (perhaps wrongly) been overtaken by theoretical thinking-long-term field studies and experimentation are required if we are to fully understand what facilitates system stability (Hooper et al. 2005).

Although both systems (biological and industrial) are clearly diverse, it is difficult to determine in which system diversity plays the more important role (Nielsen and Müller 2009). It is only with context-specific research that the roles of diversity within industrial systems can even begin to be understood. With the level and breadth of industrial data that are available — in many cases to an extent biological ecologists can only dream of - it should be possible to conduct the research needed on the evolution of functional traits and the many aspects of resource complementarity. As Mayer (2008) stated, use of such data offers great potential for advancing both ecologies.

With the number of industrial data that exist within many developed countries, it should not be difficult to go beyond concept-driven speculation and start confronting the wider diversity debate with empirical data and analysis. Indeed, the authors of this article have, in partnership with the United Kingdom's National Industrial Symbiosis Programme, started the process of mapping the industrial diversity of England (in terms of both industrial sectors and resource flows) in the pursuit of discovering how it relates to known instances of eco-industrial development and opportunities for industrial symbiosis. The work (to be published) is still at the data analysis stage, but preliminary findings have been made that not only confirm some of the most basic assumptions made within the literature of both ecologies 
but also add to some of the more complex questions on the relationship between diversity and ecosystem functioning.

It is perhaps sensible to increase diversity among power producers to ensure future energy security, but, other than possibly increasing opportunities for localized industrial symbiosis, what benefits can be drawn from the generalist prescription to promote diversity within industrial ecosystems? As can be surmised from the above discussion, individual ecosystem functioning and stability will be as dependent on the specific characteristics of potential immigrant species as they are on the collective functional (and redundant) traits of existing species. Because each ecosystem possesses a non-uniform number of resource flow compartments and internal linkages, there is arguably no way of knowing, without contextspecific research (both at and between multiple trophic levels), how diversity affects a given system. For example, there could be significant levels of diversity within a system, but the loss of just one keystone or functional species (e.g., mycorrhizal fungi within plant communities) could be disastrous in terms of maintaining what are deemed to be anthropogenically desirable conditions or, simply, levels of system production. In the same vein, without sufficient context-specific information, the artificial introduction of a new species to promote diversity could, in fact, lead to a reduction in diversity if the specific resource requirements of the immigrant lead to extinctions or promote competitive exclusion (e.g., the extinction of many animals on islands where predatory alien species have been introduced, or, within England, the wide-scale marginalization of the red squirrel [S. vulgaris] by the nonnative grays $[S$. carolinsensis $]$ ). The specific goal of maintaining or increasing the diversity of an industrial ecosystem must be clear and well thought out before prescription can be made. Diversity, in short, is a highly relative concept whose scale is largely dictated by levels of niche differentiation and realized niche overlap. Diversity, in whatever form it is observed, tends to exist where the prevailing system conditions allow it to exist.

\section{Debate Summary}

In summary, it has been shown that, at the highest level, many principles of ecology can be applied to industrial systems. For instance, the many aspects of niche theory and its role in system succession are invaluable to understanding how industrial development has taken place and will theoretically take place. Nevertheless, some widely promoted ideological principles of industrial ecology, such as the idea that ecosystems are masters of recycling, 
waste is bad, and diversity is essential to the development and stability of ecosystems, are not applicable in a universal manner. Ascertaining the effects and existence of waste within a given system and determining the contribution diversity makes to promoting stable and efficient industrial ecosystems are, among other, important questions within industrial ecology research. But, due to the complexity involved in ecological research at the community and systems levels, studies relating to their application must be conducted widely and their results presented on a case-by-case basis if any useful patterns of eco-industrial development are to be determined and made (prescriptively) transferable to similar systems.

\section{Conclusion}

A note of caution is required before one studies the dynamics of industrial ecosystems: "[Industrial] ecologists, like the [companies] organisms they study, cannot make [industry] nature conform to their perfect liking" (adapted from: Wilson 2001, 155). Thus, industrial ecosystems cannot be studied in relation to biological systems with any form of ideological preconception in mind, otherwise it will only lead to widespread false hope or misconceived disappointment.

Industrial ecology is exactly that, the ecology of industry-it is not a metaphor or paradigm for anything. Industrial ecology needs to learn and borrow from the many natural sciences, but it must not be confined by their observations of the world if theoretical and practical progress in the field is to be made. Due to the idiosyncrasies inherent within all levels of ecological structure, the principles of ecology do not manifest themselves in a universally predictable manner. Consequently, there exists a theoretical industrial ecology vacuum that needs filling with context-specific eco-industrial analysis.

The study and characterization of specific industrial ecosystems will provide the 'principles of industrial ecosystem science'. The principles will no doubt be unique to some forms of company, agglomerations, or industrial sectors; some will apply on a cross-sector basis, and some, maybe, will be applicable to all industrial ecosystems and thus be deemed law. The primary question for industrial ecology is, however, not what principles are potentially important to promoting environmentally benign manufacturing, but in what context is one principle more important than another.

Lawton (1999) stated that ecological patterns emerge most clearly at the single species level, because their study contingencies are manageable, and at larger scales, because 
general statistical order emerges from the "scrum." In contrast: "The middle ground is a mess. It is fascinating to study, and rich in wonderful biology. But by studying it, do not expect universal rules, even simple contingent general rules, to emerge. If and when they do, treasure them" (Lawton 1999, 188). It is by exploring the richness and divergence of industrial ecosystems that industrial ecology will become a respectable and defensible field in its own right, rather than through simplification and generalization of what is an inherently complex subject.

\section{Acknowledgements}

The presented article forms one element of research being conducted into regional resource planning by Paul D. Jensen in accordance with his enrollment on the University of Surrey's Engineering Doctorate (EngD) Programme in Environmental Technology. The Regional Resource Planning project is financially supported by the United Kingdom's Engineering and Physical Sciences Research Council and International Synergies Ltd. The authors would like to thank the four anonymous reviewers for their insightful comments and helpful suggestions for improving the article.

\section{References}

Ashton, W.S. 2009. The structure, function, and evolution of a regional industrial ecosystem. Journal of Industrial Ecology 13(2): 228-246.

Ayres, R.U. 2004. On the life cycle metaphor: Where ecology and economics diverge. Ecological Economics 48(4): 425-438.

Baas, L.W. and F. A. Boons. 2004. An industrial ecology project in practice: Exploring the boundaries of decision-making levels in regional industrial systems. Journal of Cleaner Production 12(8-10): 1073-1085.

Begon, M., C.R. Townsend and J.L. Harper. 2006. Ecology: From individuals to ecosystems. Fourth edition. Oxford: Blackwell.

Boons, F. and N. Roome. 2001. Industrial ecology as a cultural phenomenon: On objectivity as a normative position. Journal of Industrial Ecology 4(2): 49-54. 
Cameron, T. 2002. 2002: The year of the 'diversity-ecosystem function' debate. Trends in Ecology and Evolution 17(11): 495-496.

Cardinale, B.J., J.P. Wright, M.W. Cadote, I.T. Carroll, A. Hector, D.S. Srivastava, M. Loreau and J.J. Weis. 2007. Impacts of plant diversity on biomass production increase through time because of species complementarity. Proceedings of the National Academy of Sciences 104(46):18123-18128.

Chapman, J.L. and M.J. Reiss. 1999. Ecology: Principles and applications. Second edition. Cambridge, UK: Press Syndicate of the University of Cambridge.

Chertow, M. R. 2007. “Uncovering” industrial symbiosis. Journal of Industrial Ecology 11(1): 11-30.

Colyvan, M. and L.R. Ginzburg. 2003. Laws of nature and laws of ecology. Oikos 101(3): 649-653.

Côté, R.P. and T. Smolenaars. 1997. Supporting pillars for industrial ecosystems. Journal of Cleaner Production 5(1-2): 67-74.

Deutz, P. and D. Gibbs. 2008. Industrial ecology and regional development: Eco-industrial development as cluster Policy. Regional Studies 42(10): 1313-1328.

Ehrenfeld, J. 2003. Putting a spotlight on metaphors and analogies in industrial ecology. Journal of Industrial Ecology 7(1): 1-4.

Ehrenfeld, J. and N. Gertler. 1997. Industrial ecology in practice: The evolution of interdependence at Kalundborg. Journal of Industrial Ecology 1(1): 67-80.

Flombaum, P. and O.E. Sala. 2008. Higher effect of plant species diversity on productivity in natural than artificial systems. Proceedings of the National Academy of Sciences 105(16): 6087-6090.

Frosch, R.A. and N.E. Gallopoulos. 1989. Strategies for manufacturing. Scientific American 261(3): 144-152.

Gallopoulos, N.E. 2006. Industrial ecology: An overview. Progress in Industrial Ecology An International Journal 3(1-2): 10-27.

Gibbs, D. 2008. Industrial symbiosis and eco-industrial development: An introduction. Geography Compass 2(4): 1138-1154. 
Gibbs, D. and P. Deutz. 2005. Implementing industrial ecology? Planning for eco-industrial parks in the USA. Geoforum 36(4): 452-464.

Gibbs, D. and P. Deutz. 2007. Reflections on implementing industrial ecology through ecoindustrial park development. Journal of Cleaner Production 15(17): 1683-1695.

Graedel, T.E. 1996. On the concept of industrial ecology. Annual Review of Energy and the Environment 21(69-98): 69-98.

Hansson, L. 2003. Why ecology fails at application: Should we consider variability more than regularity? Oikos 100(3): 624-627.

Hardy, C. and T.E. Graedel. 2002. Industrial ecosystems as food webs. Journal of Industrial Ecology 6(1): 29-38.

Harte, J. 2001. Business as a living system: The value of industrial ecology (a roundtable discussion). California Management Review 43(3): 16-25.

Hooper, D.U., F.S. Chapin III, J.J. Ewel, A. Hector, P. Inchausti, S. Lavorel, J.H. Lawton, D.M. Lodge, M. Loreau, S. Naeem, B. Schmid, H. Setala, A.J. Symstad, J. Vandermeer and D.A. Wardle. 2005. Effects of biodiversity on ecosystem functioning: a consensus of current knowledge. Ecological Monographs 75(1): 3-35.

Jelinski, L.W., T.E. Graedel, R.A. Laudise, D.W. McCall and C. K. N. Patel. 1992. Industrial ecology: concepts and approaches. Proceedings of the National Academy of Sciences 89(3): 793-797.

Jørgensen, S.E. 2002. Integration of ecosystem theories: A pattern. Third edition. Dordrecht: Kluwer Academic Publishers.

Korhonen, J. 2001a. Four ecosystem principles for an industrial ecosystem, Journal of Cleaner Production 9(3): 253-259.

Korhonen, J. 2001b. Some suggestions for regional industrial ecosystems - Extended industrial ecology. Eco-Management and Auditing 8(1): 57-69.

Korhonen, J. 2005. Do we really need the debate on the natural ecosystem metaphor in technology management and sustainable development literature? Clean Technologies and Environmental Policy 7(1): 33-41. 
Korhonen, J., F. von Malmborg, P.A. Strachan, and J.R. Ehrenfeld. 2004. Management and policy aspects of industrial ecology: An emerging research agenda. Business Strategy and the Environment 13(5): 289-305.

Korhonen, J. and J-P. Snäkin. 2005. Analysing the evolution of industrial ecosystems: Concepts and application. Ecological Economics 52(2): 169-186.

Lange, M. 2005. Ecological laws: What should they be and why would they matter? Oikos 110(2): 394-403.

Lawton, J.H. 1999. Are there general laws in ecology? Oikos 84(2): 177-192.

Levine, S.H. 2003. Comparing products and production in ecological and industrial systems. Journal of industrial ecology 7(2): 33-42.

Liwarska-Bizukojc, E., M. Bizukojc, A. Marcinkowski and A. Doniec. 2009. The conceptual model of an eco-industrial park based upon ecological relationships. Journal of Cleaner Production 17(8): 732-741.

Lotka, A.J. 1922a. A contribution to the energetics of evolution. Proceedings of the National Academy of Science 8(6): 147-151.

Lotka, A.J. 1922b. Natural selection as a physical principle. Proceedings of the National Academy of Science 8(6): 151-154.

Mayer, A.L. 2008. Ecologically-based approaches to evaluate the sustainability of industrial systems. International Journal of Sustainable Society 1(2): 117-133.

McCann, K.S. 2000. The diversity-stability debate. Nature 405(6783): 228-233.

McManus, P. and D. Gibbs. 2008. Industrial ecosystems? The use of tropes in the literature of industrial ecology and eco-industrial parks. Progress in Human Geography 32(4): 525-540.

Nielsen, S.N. 2007. What has modern ecosystem theory to offer cleaner production, industrial ecology and society? The views of an ecologist. Journal of Cleaner Production 15(17): 1639-1653.

Nielsen S.N. and F. Müller. 2009. Understanding the functional principles of nature Proposing another type of ecosystem services. Ecological Modeling 220(16): 19131925.

Odum, E.P. 1969. The strategy of ecosystem development. Science 164(3877): 262-270. 
Odum, H.T. and R.C. Pinkerton. 1955. Time's speed regulator: the optimum efficiency for maximum power output in physical and biological systems. American Scientist 43(2): $331-343$.

O'Hara, R.B. 2005. The anarchist's guide to ecological theory. Or, we don't need no stinkin' laws. Oikos 110(2): 390-393.

Pfister, A.B. and B. Schmid. 2002. Diversity-dependent production can decrease the stability of an ecosystem. Nature 416(6876): 84-86.

Roberts, B.H. 2004. The application of industrial ecology principles and planning guidelines for the development of eco-industrial parks: an Australian case study. Journal of Cleaner Production 12(8-10): 997-1010.

Schneider, E.D. and J.J. Kay. 1994. Life as a manifestation of the second law of thermodynamics. Mathematical and Computer Modelling 19(6-8): 25-48.

Sterr, T and T. Ott. 2004. The industrial region as a promising unit for eco-industrial development - reflections, practical experience and establishment of innovative instruments to support industrial ecology. Journal of Cleaner Production 12(8-10): 947-965.

Tilman, D., P.B. Reich, J. Knops, D. Wedin, T. Mielke and C. Lehman. 2001. Diversity and productivity in a long-term grassland experiment. Science 294(5543): 843-845.

Wells, P.E. 2006. Re-writing the ecological metaphor: Part 1. Progress in Industrial Ecology - An International Journal 3(1/2): 114-128.

Westoby, M. 1997. What does 'ecology' mean? Trends in Ecology and Evolution 12(4): 166.

Wilson, E.O. 2001. The diversity of life. Reprint edition. London: Penguin Books.

Wilson, E.O. 2004. On human nature, Second edition. Cambridge, MA, USA: Harvard University Press.

\section{About the Authors}

Paul D. Jensen is a research engineer at the National Industrial Symbiosis Programme and the University of Surrey's Centre for Environmental Strategy (CES) in Guildford, Surrey, UK. Lauren Basson is a lecturer at CES, and Matthew Leach is a professor and director of CES. 


\section{Notes}

${ }^{1}$ Principle: an observed or logically proven statement of truth.

${ }^{2}$ For example, the laws of thermodynamics (widely employed in ecosystem development research) derive from the study of physics.

${ }^{3}$ Law: a principle (or collection of related principles) that is true without exception.

4 "Autoecological" pertains to the ecological study of a single species of organism.

${ }^{5}$ Fundamental niche: the complete range of niches an organism can fill in the absence of competition.

${ }^{6} \mathrm{~A}$ "sere" refers to the sequential change in the composition of an ecological community during the process of succession.

${ }^{7}$ Allogenic (succession): a change to community composition as a result of external environmental influences.

${ }^{8}$ Although the realization of a fundamental niche is described here as being achieved as a result of local adaption, parallel and convergent evolution show that the development of a given 'phenotype' is capable of replication wherever suitable conditions exist.

${ }^{9}$ Although, as a caveat to this statement, it should be noted that diverse plant communities can take several generations of growing seasons before complementarity facilitates system production on scales greater than that of highly productive monocultures (see Cardinale et al. 2007). 